\title{
Evaluation of ABS patterns produced from FDM for investment casting process
}

\author{
W. S. W. Harun ${ }^{1}$, S. Safian ${ }^{2} \&$ M. H. Idris ${ }^{2}$ \\ ${ }^{1}$ Faculty of Mechanical Engineering, U niversiti Malaysia Pahang, \\ Malaysia \\ ${ }^{2}$ Faculty of Mechanical Engineering, Universiti Teknologi Malaysia, \\ Malaysia
}

\begin{abstract}
The paper presents the investigation of the Acrylonitrile Butadiene Styrene (ABS) pattern produced from Fused Deposition Modeling (FDM) for use as a pattern for an investment casting process. The investigations were carried out to establish the physical and collapsibility characteristics of an H-shape pattern produced from two different construction methods, i.e. hollow and solid, using rapid prototyping FDM2000 machine. Surface roughness, dimensional accuracy and distortion were evaluated to establish the physical characteristics of the pattern constructed. Results on surface roughness showed no significant variation between hollow and solid constructed patterns. As for dimensional accuracy, hollow patterns produced better accuracy compared to solid patterns. However, the result on distortion shows that hollow constructed patterns experienced $33.11 \%$ higher than solid constructed patterns. For collapsibility investigation, shell investment casting mould built from the two different pattern construction methods were fired to a temperature ranging from $300^{\circ} \mathrm{C}$ to $600^{\circ} \mathrm{C}$. The moulds were weighted at a predetermine temperature intervals to establish the collapsibility characteristic of the patterns. ABS (P400) was found feasible to be used as an investment casting pattern material. Hollow pattern construction proved to be more viable than solid pattern construction in terms of dimensional accuracy, mould cleanliness, pattern collapsibility and no mould cracking at all temperatures.
\end{abstract}

Keywords: ABS, FDM, investment casting. 


\section{Introduction}

Investment casting process (IC) is a metal casting technique capable of providing an economical means of mass production components with complex features such as thin walls, undercut contours and inaccessible spaces which are difficult or impossible to produce using other fabrication methods (Beeley [3]). Despite the wide range of applications in many industries, the standard (conventional) IC process practice in modern foundries has its drawbacks. High tooling costs and lengthy lead times are associated with the fabrication of metal moulds required for producing the sacrificial wax patterns used in IC (Sachs et al. [11]). The high tooling costs involved in conventional IC results in cost justification problems when small numbers of castings are required.

Rapid prototyping (RP) techniques are fast becoming standard tools in the product design and manufacturing industries. With the capability of rapidly fabricating 3D physical objects, RP has become an indispensable tool employed for shortening new product design and development time cycles (Hilton and Jacobs [7], Chua and Leong [5], Wohlers [13]). RP techniques are unlimited either by the geometry or by the complexity of the parts to be fabricated.

In addition, RP techniques involve no tooling or fixtures, resulting in simpler set up, lower overhead cost and shorter production lead times compared to other fabrication methods. With RP, parts that were previously impossible or extremely costly and time-consuming to fabricate can be built with ease.

The application of RP-fabricated patterns as substitutes for the traditional wax patterns employed in IC stems from the fact that RP materials can be melted and burned out from the ceramic shell (ceramic shell casting) without damaging it (Beaman et al. [2]). Most commercialized RP techniques are capable of producing such patterns that can be used directly in IC.

ABS plastics are a family of opaque thermoplastic resins formed by copolymerizing acrylonitrile, butadiene, and styrene (ABS) monomers. ABS plastics are primarily notable for especially high impact strengths coupled with high rigidity or modulus. Consisting of particles of a rubberlike toughener suspended in a continuous phase of styreneacrylonitrile (SAN) copolymer, ABS resins are hard, rigid, and tough, even at low temperatures. ABS parts are strong and able to withstand the rigors of transportation. In addition, the surface finish of ABS parts is proved to be far better than RP wax. On the contrary, the previous RP wax produced patterns are very fragile, thus transportation within foundry could yield multiple parts. Besides, the softening point of RP wax is as low as $77^{\circ} \mathrm{C}$, which can be reached in the hot sun.

The study was aimed at evaluating the physical and collapsibility characteristics of the Acrylonitrile-butadiene-styrene (ABS) P400 produced from a commercial fused deposition modeling (FDM) model FDM2000. Surface quality, dimensional accuracy, distortion, and collapsibility characteristics were compared between solid and hollow constructed pattern. 


\subsection{Procedure}

Four H-shape specimens from each construction method; solid and hollow, were produced using rapid prototyping FDM2000 machine. The specimens were designated as $\mathrm{S}$ and $\mathrm{H}$ for solid and hollow patterns respectively. The patterns were evaluated with respect to their dimensions, surface roughness and distortion. The patterns were then used to build ceramic shell moulds before being burned at temperatures between $300^{\circ} \mathrm{C}$ and $600^{\circ} \mathrm{C}$.

\subsubsection{Specimens preparation}

The H-shape specimen (Figure 1) were designed taking into consideration the

- Complexity of the shape for the easy removal of the ABS pattern from the mould;

- Complexity of features, which can distort the shape easily; so that the variation between solid and hollow pattern can be compared.

AutoCAD $2005^{\circledR}$ software was used to produce a 3D CAD model for the Hshape specimen as shown in Figure 1. It was then transferred to the intermediate software (QuickSlice ${ }^{\circledR}$ ) for process setting. From 3D CAD, the file was converted into Stereolithography (STL) file format before being sent to the FDM machine for fabrication.

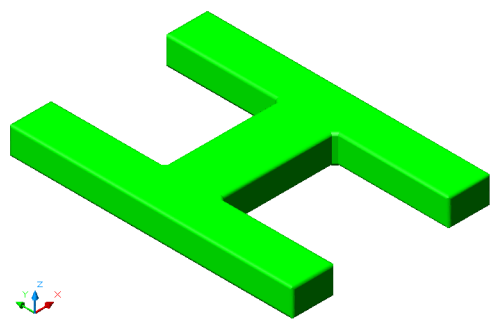

Figure 1: A 3D CAD H-shape specimen model produced from AutoCAD $2005^{\circledR}$ software.

In general the CAD parameters used to build the solid and hollow H-shape specimens were the same. However, modifications were made on the air gap and raster angle to create differences between solid and hollow internal feature. The internal feature of hollow specimen consists of large air gaps with $45^{\circ} /-45^{\circ}$ raster angle whilst $0 \mathrm{~mm}$ air gaps and $0^{\circ}$ of raster angle for solid specimen (Lee et al. 2005). The option for producing hollow pattern can be set by applying a "Fast mode" option offered by QuickSlice ${ }^{\circledR}$ software. Similarly no "fast mode" option could be set for the solid specimen. Figures 2(a) and (b) show the H-shape solid and hollow specimens respectively. The FDM process parameters for both types of specimen are shown in Table 1. 


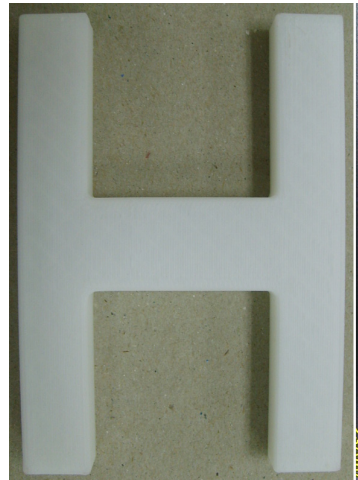

(a)

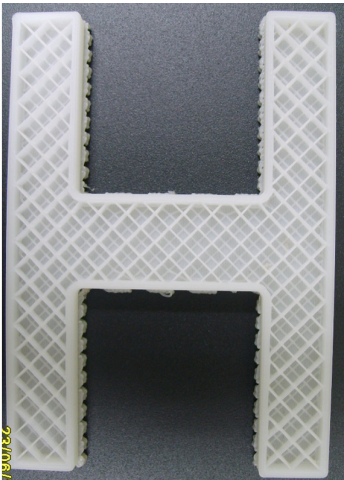

(b)

Figure 2: The H-shape specimens used in the investigation (a) solid construction (b) hollow construction.

Table 1: $\quad$ FDM2000 setting parameters.

\begin{tabular}{cl}
\hline Setting Parameters & Value \\
\hline Nozzle tip size & $0.0016 \mathrm{in}$ \\
Raster Angle & $45^{\circ} / 0^{\circ}$ \\
Air gap & $45 / 0 \mathrm{~mm}$ \\
Slice thickness & $0.2540 \mathrm{~mm}$ \\
Wipe tip & All \\
Support thickness & 10 layers \\
Support style & Sparse \\
Liquefier temperature & $265^{\circ} \mathrm{C}$ \\
Envelope temperature & $70^{\circ} \mathrm{C}$ \\
\hline
\end{tabular}

\subsubsection{Measurement of surface roughness (SR)}

The surface roughness measurement on the ABS patterns was made by using a Mitutoyo FORMTRACER CS-5000 with cut-off value $(L c)$ of $0.8 \mathrm{~mm}$. The FORTRACEPAK ${ }^{\circledR}$ software was directly connected to the machine that analyzes and provides the value of surface roughness measured. A total of 14 surfaces with three measurements on each surface were conducted for each pattern.

\subsubsection{Dimensional accuracy (DA) measurement}

A total of 26 dimensions were measured. The dimensions were measured using profile projector Mitutoyo PJ-3000 with the accuracy of $1 \mu \mathrm{m}$.

\subsubsection{Measurement of distortion (D)}

The degree of distortion was determined by the difference between measurements A and B as shown in Figure 3. 


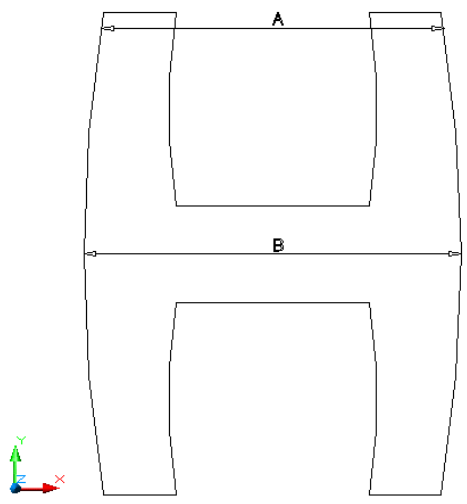

Figure 3: The dimensions measured to determine the degree of distortion in the ABS pattern.

Table 2: The setting condition with holding and cooling time is 1 hour and 12 hours each.

\begin{tabular}{cccc}
\hline Solid & \multicolumn{3}{c}{ Hollow } \\
\hline Specimen & Temp. & Specimen & Temp. \\
\hline S1 & $300^{\circ} \mathrm{C}$ & $\mathrm{H} 1$ & $300^{\circ} \mathrm{C}$ \\
S2 & $400^{\circ} \mathrm{C}$ & $\mathrm{H} 2$ & $400^{\circ} \mathrm{C}$ \\
S3 & $450^{\circ} \mathrm{C}$ & $\mathrm{H} 3$ & $450^{\circ} \mathrm{C}$ \\
S4 & $500^{\circ} \mathrm{C}$ & $\mathrm{H} 4$ & $500^{\circ} \mathrm{C}$ \\
Extra S1 & $550^{\circ} \mathrm{C}$ & Extra $\mathrm{H} 1$ & $550^{\circ} \mathrm{C}$ \\
Extra S2 & $600^{\circ} \mathrm{C}$ & Extra $\mathrm{H} 2$ & $600^{\circ} \mathrm{C}$ \\
\hline
\end{tabular}

\subsubsection{Collapsibility test of ABS H-shape patterns}

The ceramic moulds that were built from both solid and hollow patterns were fired at the temperature between $300^{\circ} \mathrm{C}$ and $600^{\circ} \mathrm{C}$ (Stratasys Inc. [12]). A digital weighing machine (Precisa XT 6200C) was used to measure the weight loss of specimens as the temperature is increased. The reduction in weight indicates the decomposition or collapsibility volume/weight of the specimen. Prior to burning the moulds were weighed to establish the initial weight of the pattern. The mould was placed in the furnace in an inverted position to ease the flow of the molten pattern material from the mould. The furnace was heated at an average rate of between $2^{\circ} \mathrm{C} / \mathrm{min} 10^{\circ} \mathrm{C} / \mathrm{min}$ (British Standards Institution [4]). When the required temperature is attained, the shell moulds; hollow and solid, were placed inside the furnace and left for 1 hour. The moulds were then left to cool for 12 hours inside the furnace before it is weighed. The same procedure was repeated for the other temperatures. Table 2 shows the summarized procedure for the 
burning process. The weight difference between before and after the burning process indicates the collapsibility characteristic of the pattern for a particular temperature.

\section{Results and discussion}

\subsection{Surface roughness (SR)}

The surface B (interface between ABS and its support material) recorded the highest $R a$ value for all pattern compared to other surfaces. Solid pattern, S4, recorded the highest $R a$ value of $32.13 \mu \mathrm{m}$. Similar trend was observed on surface A (top surface of ABS pattern), where it recorded comparatively low value of $\mathrm{Ra}$ for all pattern. Hollow specimen, $\mathrm{H} 2$, was found to record the lowest Ra value of $6.17 \mu \mathrm{m}$. The rest of the studied surfaces recorded almost a constant trend for both solid and hollow patterns with $R a$ values ranges between $17.00 \mu \mathrm{m}$ to $19.00 \mu \mathrm{m}$. The extreme values were only observed for surface A and B. It is observed that surface A is the final finishing horizontal surface whilst surface B is the surface which is in contact with the support materials whilst other surfaces are side surfaces developed as a result of layer building. The value of these surfaces will depend on the slice thickness which is in this case $0.254 \mathrm{~mm}$. Thinner slice layer may reduce the surface $R a$ value. This is in line with the finding of the previous researcher (Azanizawati [1]) where better surface finish was found to mainly due to the low layer thickness. Surface finish for rapid prototyping pattern was found to be dependent on the lower degrees of the build orientation) and pattern air gap (Pandey et al. [9].

\subsection{Dimensional accuracy (DA)}

The bar chart in Figure 4 shows the relationship of percentages deviation versus dimensional location for both types of specimen. It can be seen that, there is no sign of typical distribution trend of the measured specimens. In other word, the recorded data revealed that inconsistency of deviation's phenomena had occurred at difference locations. Among the 208 of the dimensional locations, the highest percentage of deviation was found at location 22 on solid specimen S4 with deviation value of $1.23 \%$. Follow by $1.14 \%$, which occurred at location 2 on solid specimen S3. Hollow specimens recorded lower deviation value than solid. It is suggested that the higher percentage of deviations occurred on solid patterns as compared to hollow pattern. The mean average deviation value of hollow patterns was $26.40 \%$ lower than the solid patterns. The average deviation value of solid patterns was within $0.356 \pm 0.56 \%$ while for hollow pattern was $0.262 \pm$ $0.33 \%$. These phenomena occurred due to internal structures of the patterns. During cooling, the pattern experienced internal stresses in the interior structures which may cause the pattern to shrink. The solid structures experienced higher internal stresses than hollow structures because of the higher density of the internal structure. As a result the final accuracy of the solid patterns was significantly affected as compared to hollow pattern. 


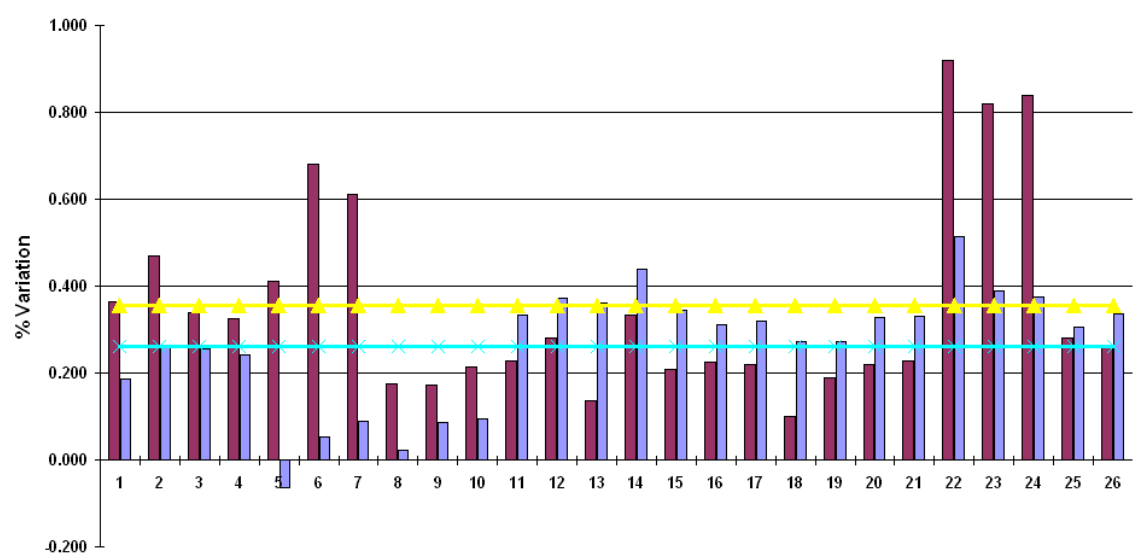

Dimensional Location

Solid Average $\square$ Hollow Average - Mean of Solid Average $\longleftarrow$ Mean of Hollow Average

Figure 4: Average value of DA for solid and hollow pattern construction.

\subsection{Distortion (D)}

The distortions of the ABS patterns obtained from both solid and hollow construction patterns were plotted as shown in Figure 5. Results show that the ABS patterns of hollow construction distorted $33.11 \%$ more than solid construction patterns. The variations of hollow patterns were within $0.148 \pm$ $0.108 \mathrm{~mm}$, while those of solid patterns were within $0.099 \pm 0.032 \mathrm{~mm}$. It was also observed that the distortion of the ABS (P400) from the current study is less than wax pattern of similar shape reported by other researcher (Prasad et al. 2003).

\subsection{ABS collapsibility}

From the graph plotted in Figure 6, it is observed that $90 \%$ of the patterns from both construction types both were burned-off between the temperature of $300^{\circ} \mathrm{C}$ and $400^{\circ} \mathrm{C}$. The patterns were completely burned-off at the temperature of $500^{\circ} \mathrm{C}$. However, at that temperature a small amount of ash was observed at the internal wall of the empty shell mould. No ash was visible when the temperature was increased to the temperature above $550^{\circ} \mathrm{C}$.

During burning process, cracks were observed on the shell of the solid construction pattern at the burning temperatures of $300^{\circ} \mathrm{C}, 400^{\circ} \mathrm{C}, 450^{\circ} \mathrm{C}$, and $500^{\circ} \mathrm{C}$. This may be due to the expansion of the ABS pattern when subjected to heating conditions. It is an establish fact that in burning of shell investment casting mould, the different in thermal expansion between the pattern wax and shell would cause the shell to crack. The wax pattern expands and exerts force on the shell which resulted in cracking of the shell mould. The same phenomenon may have happened with ABS pattern under study. Cracks may also develop if 
pattern wax is not fully melted and left inside the mould. This may explains why the shell burned at the temperature of $500^{\circ} \mathrm{C}$ cracks.

On the contrary, at temperatures $550^{\circ} \mathrm{C}$ and $600^{\circ} \mathrm{C}$ no crack was observed. Theoretically, at high temperature, pattern material at the interface melted and provides a thin gap at the interface between the pattern material and the shell before the bulk pattern material expands. This will 'reduce' the force exerted directly onto the shell, thus avoiding the shell from cracking. For moulds developed from hollow construction pattern, no crack was observed at all temperatures. The thin internal $45^{\circ}$ hatching constructions may have melted first compared to the solid surface/interface. This allows the pattern to collapse inwards before the bulk of the material expands, thus avoiding the shell from cracking.

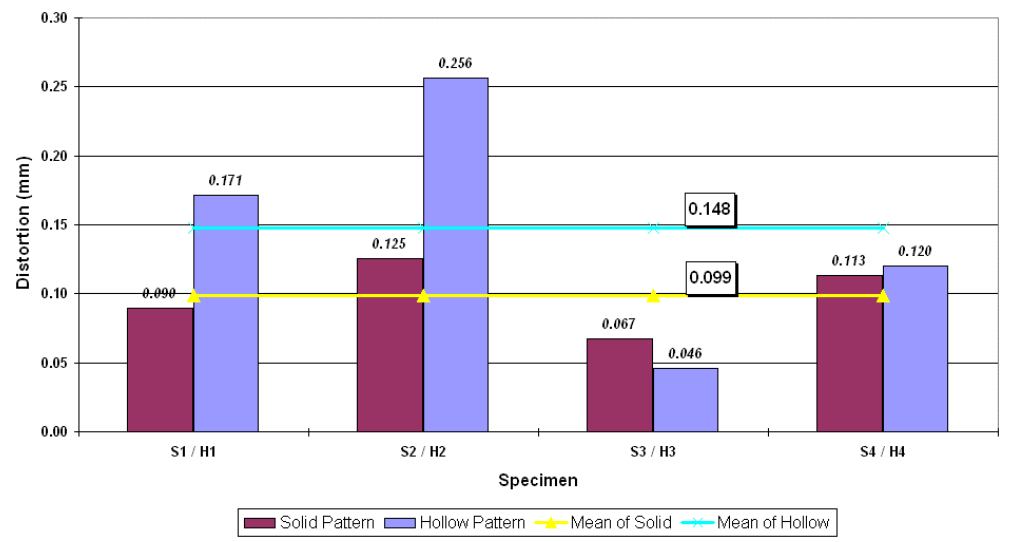

Figure 5: Distortion of solid and hollow construction ABS patterns.

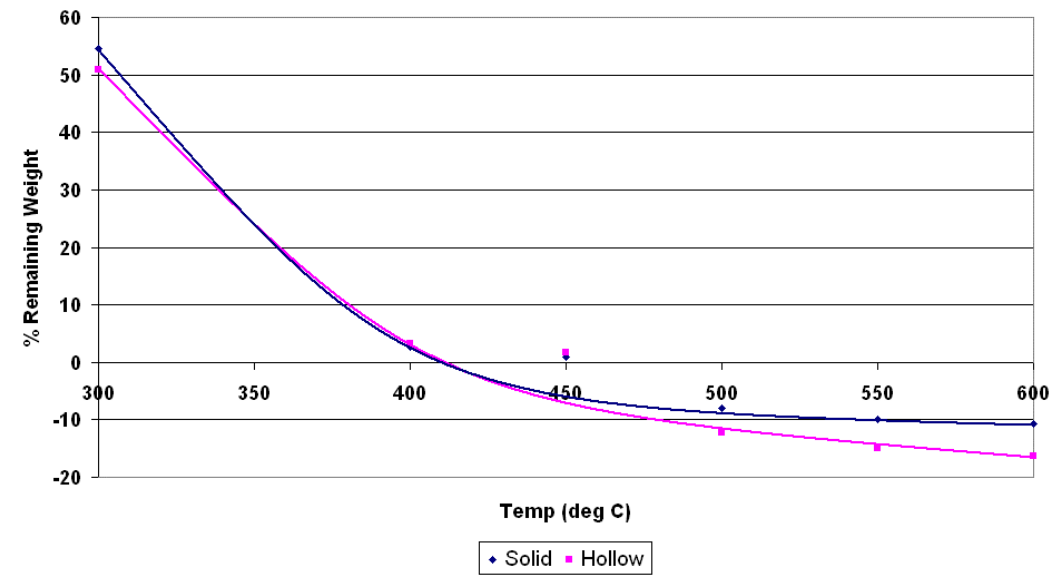

Figure 6: Graph plotted for pattern collapsibility analysis. 


\section{Conclusion}

Based on the investigations conducted, several conclusions can be made:

i Both hollow and solid pattern constructions produced the same surface roughness at the determine location measured. For both pattern constructions, the upper surface was found to be better in surface quality when compared to the bottom surface which was supported by the support materials. The surface roughness of the side surfaces depend on the slice thickness of each deposited layer.

ii The hollow pattern proved to have better dimensional accuracy compared to solid pattern construction.

iii The hollow pattern construction distorted $33.11 \%$ more than the solid pattern construction.

iv Both pattern constructions show similar collapsibility pattern. However, the hollow pattern shows no mould cracking at all burning temperatures.

\section{References}

[1] Azanizawati, M. (2003) Quality Assessment of Hollow Rapid Prototyping Model, Master's Thesis, Universiti Teknologi Malaysia.

[2] Beaman, J.J., Barlow, J.W., Bourell, D.L., Crawford, R.H., Marcus, H.L., McAlea, K.P. (1997) Solid Freeform Fabrication: A New Direction in Manufacturing, Kluwer, Dordrecht.

[3] Beeley, P.R. (1995) Smart RF investment casting, The Institute of Materials.

[4] British Standards Institution (1984) BS1902: Methods of Testing Refractory Materials, BSI, London.

[5] Chua, C.K., Leong, K.F. (1997) Rapid Prototyping: Principles and Applications in Manufacturing, Wiley, New York.

[6] Elias, N.F. (2001) Performance Evaluation of Rapid Prototyping Process, Master's Thesis, Universiti Teknologi Malaysia.

[7] Hilton, P.D., Jacobs, P.F. (2000) Rapid Tooling: Technologies and Industrial Applications, Marcel Dekker, New York.

[8] Lee, B.H., Abdullah, J., Khan, Z.A. (2005) Optimization of rapid prototyping parameters for production of flexible ABS object. Journal of Materials Processing Technology, 169, 54-61.

[9] Pandey, P.M., Reddy, N.V., Dhande, S.G. (2003) Improvement of surface finish by staircase machining in fused deposition modeling, Journal of Material Processing Technology, 132, 323-331.

[10] Prasad, K.D., Yarlagadda, V., Teo, S.H. (2003) Statistical analysis on accuracy of wax patterns used in investment casting process, Journal of Material Processing Technology, 138, 75-81.

[11] Sachs, E., Cima, M., Cornie, J. (1991) Three-dimensional printing: ceramic shells and cores for casting and other applications. Proceedings of 2nd international conference on rapid prototyping, Dayton, $\mathrm{OH}, 39-53$. 
328 Computational Methods and Experiments in Materials Characterisation IV

[12] Stratasys, Inc. (1998) Investment Casting Using FDM/ABS Rapid Prototype Patterns, Trade report, USA.

[13] Wohlers, T. (2000) Wohlers Report: Rapid Prototyping \& Tooling State of the Industry Annual Worldwide Progress Report, Wohlers Associates, USA. 